Original Research Article

\title{
Predicting evolution of insect resistance to transgenic crops in within-field refuge configurations, based on larval movement
}

\author{
Adriano G. Garcia ${ }^{\mathrm{a}, *}$, Cláudia P. Ferreira ${ }^{\mathrm{b}}$, Fernando L. Cônsoli ${ }^{\mathrm{a}}$, Wesley A.C. Godoy \\ a Department of Entomology and Acarology, University of São Paulo, ESALQ USP, Piracicaba, SP 13418-900, Brazil \\ ${ }^{\mathrm{b}}$ Biostatistics Department, IBB, UNESP, Botucatu, SP 18618-000, Brazil
}

\section{A R T I C L E I N F O}

\section{Article history:}

Received 13 November 2015

Received in revised form 15 July 2016

Accepted 20 July 2016

Available online 17 August 2016

\section{Keywords:}

Cellular automata

Transgenic crops

Resistance management

Refuge areas

Insect ecology

\begin{abstract}
A B S T R A C T
The selection pressure imposed by the widespread use of transgenic technologies can lead to the evolution of insect resistance, and the availability of refuge areas that allow susceptible homozygous insects to survive is a key factor in delaying the evolution of resistance in agricultural landscapes. Different strategies to exploit refuge areas exist, but several insect-related ecological traits may directly affect the efficiency of refuges in slowing the development of resistance. Insect larval movement is one such trait that may affect the management of resistance, depending on the refuge strategy adopted. We developed a computational model to simulate how larval movement would affect the spatio-temporal dynamics of the evolution of resistance of insect pests to Bt crops, under different refuge configurations. In order to test the model, we used population data for Spodoptera frugiperda, one of the main target pests for control with $B t$ toxins. Simulations were run for spatial arrangements composed of three refuge configurations (seed mixture, blocks, and strips), with sizes ranging from $20 \%$ to $50 \%$ for two types of resistance (incomplete and complete) and three rates of larval movement (proportion of larvae moving per time step), equal to $0,0.1$ and 0.5 . We demonstrated that with a seed mixture, in most cases the higher the rate of larval movement, the higher the proportion of resistant insects in the population in an area, regardless of the type of resistance tested. Strip configurations showed the opposite trend. In a block configuration, the number of resistant larvae was highest at an intermediate dispersal rate $(0.1)$. We concluded that larval movement is an important variable affecting the evolution of resistance to Bt crops, but its effect depends on the type of resistance and the configuration and size of the refuge.
\end{abstract}

(c) 2016 Elsevier B.V. All rights reserved.

\section{Introduction}

Increased concern regarding the side effects caused by the indiscriminate use of pesticides to the environment and non-target organisms has motivated the development of new pest-control strategies (Thacker, 2002). One of these technologies involves the use of transgenic crops, most of them genetically altered to express genes from the bacterium Bacillus thuringiensis (Bt plants). The increasing use of $B t$ plants, together with the low level of compliance with refuge requirements, have raised concern. The lack of compliance with guidelines for the use of refuges has favored the evolution of insect resistance to Bt plants in the field, and has led to the rapid nullification of some of the commercially available technologies (James, 2013; Tabashnik et al., 2013).

\footnotetext{
* Corresponding author.

E-mail address: adrianogomesgarcia@usp.br (A.G. Garcia).
}

One strategy to delay the evolution of insect resistance to $B t$ toxins is the use of refuges. This consists of planting non-Bt crops in order to promote the survival of susceptible insects that will outnumber the resistant ones, preventing an increase in the proportion of the resistant phenotype when resistance is a recessive trait (Sisterson et al., 2005; Crowder and Carrière, 2009). Different countries have adopted different requirements for refuge areas. For instance, in the United States, the Environmental Protection Agency (EPA) has determined that the optimum proportions of non-Bt refuge areas are $20 \%$ for $B t$-maize fields in the Corn Belt and 50\% for Bt-maize fields in the Cotton Belt, based on scientific criteria and practicality for growers (Environmental Protection Agency, 1998). In Brazil, the Ministry of Agriculture, Livestock and Food Supply recommends $10 \%$ non-Bt plants in Btmaize fields, $20 \%$ in Bt-soybean fields, and 5\% to 20\% in Bt-cotton fields (Ministry of Agriculture, Livestock and Food Supply, 2014).

Usually, the refuge is structured as a block or a set of strips of non-Bt and Bt crops (Carroll et al., 2013). An alternative to the structured refuge is the use of seed mixtures of non-Bt and Bt crops 
(RIB) to ensure growers' compliance with refuge requirements (Carroll et al., 2012, 2013). Although RIB appears to be a plausible solution for managing the evolution of insect resistance to Bt crops, several important issues related to the effect of insect larval movement on the evolution of resistance remain to be resolved. Larval movement can expose more larvae to sublethal doses of $B t$ toxins, increasing selection for $B t$ resistance either if the target pest moves as early instars from $B t$ to non- $B t$ crops, or if it moves from non-Bt to Bt crops as older instars (Binning et al., 2014; Head et al., 2014).

Spodoptera species (Lepidoptera: Noctuidae) are among the main target pests for control with $B t$ toxins in maize and cotton crops, and insect-resistance management is essential to ensure the effectiveness of this control (Huang et al., 2014). Spodoptera frugiperda (J.E. Smith, 1797) is the main species occurring in the New World, with a distribution ranging from Argentina to Canada (Sparks, 1979), where Bt plants are extensively cultivated. Because of the heavy use of $B t$ plants, field-evolved resistance to $B t$ maize has already been documented in Puerto Rico (Vélez et al., 2013) and Brazil (Farias et al., 2014; Omoto et al., 2016).

Ecological modeling can be a useful tool to investigate the influence of larval movement and other ecological factors on the evolution of resistance (Sisterson et al., 2005). Theoretical ecological models that include spatial heterogeneity and insect fitness on different hosts (e.g., Bt or non-Bt crops) can provide insights on this evolution. Cellular automata (CA) are an interesting choice for developing these ecological models, because all relevant within-plot characteristics of a crop can be included in the model (Garcia et al., 2014). The discrete nature of CA models permits one to represent the presence or absence of the different stages of the insect pest at a specific position of the lattice, by a binary variable whose state can change over time through simple stochastic rules that mimic an insect life cycle (Hiebeler, 2005; Garcia et al., 2014). Additionally, a combination between CA and individual-based approaches may provide a realistic sense of movement since CA models focus on the spatial conformation of the variables through transitions rules while individual-based models focus on the variability of individual characteristics (Jorgensen and Chon, 2009).

In order to investigate the effect of larval movement of $S$. frugiperda on the evolution of resistance under different $B t$ refuge configurations, we developed a CA model. We ran simulations testing three different rates of larval dispersal under three refuge configurations (seed mixture, strips, and blocks), and with refuge areas ranging in size from 20 to $50 \%$ of the total cultivated area. We also considered the type of resistance (complete or incomplete) to $B t$ maize, since this attribute may influence the selection of the resistant phenotype. According to Tabashnik et al. (2013), incomplete resistance occurs when resistant insects developing on $B t$ crops are at a disadvantage compared with those that develop on non-Bt maize. In each simulation, we determined the proportion of resistant larvae per time step. We hypothesized that larval movement would differently affect the evolution of resistance to $B t$ crops, for complete or incomplete resistance mechanisms, under different configurations and proportions of refuges.

Many different studies have focused on the evolution of insect resistance to transgenic crops, including considerations of spatiality. A model based on a reaction-diffusion system of partial differential equations (PDEs), combining a spatial demographic model of population dynamics with classical genetic theory, was used to study the relationship between refuge size, pest movement, and resistance evolution in the European corn borer, Ostrinia nubilalis (Lepidoptera: Crambidae), and showed that contiguous refuge areas are more efficient than a large number of small refuge patches (Tyutyunov et al., 2008). A stochastic model was developed to simulate the rate of resistance evolution of Helicoverpa armigera (Lepidoptera: Noctuidae) to Cry1AC in India, integrating genetic and ecological parameters (Kranthi and Kranthi, 2004). They were able to define the time spans necessary to reach a resistant allele frequency of 0.5 for different proportions of Bt cotton in the total area. Kang et al. (2014) developed a spatial explicit model of population dynamics and genetics of Diatraea saccharalis (Lepidoptera: Crambidae) to investigate the evolution of $B t$ resistance in a landscape composed of $B t$ and non-Bt maize, sorghum, and rice fields, and concluded that the landscape heterogeneity may complicate the management of $B t$ resistance in $D$. saccharalis. In order to study specifically the resistance evolution in S. frugiperda,Téllez-Rodríguez et al. (2014) developed a two-patch population model to investigate the effect of a preference for oviposition on $B t$ or non-Bt crops on resistance evolution. They concluded that the avoidance of damaged leaves (which led females to lay eggs on $B t$ plants rather than on plants in the refuge areas) rendered the refuge strategy ineffective. However, none of these previous modeling investigations considered larval movement.

Among the spatial models that have been proposed to study the relationship between larval movement and the evolution of insect resistance, Cerda and Wright (2004) developed a population-based model to test the effects of different refuge proportions (5\%-50\%) and different refuge configurations (border, central, equidistant random) on the frequency of resistant alleles in hypothetical populations. They reported that the larger the refuge sizes, the lower the rates of increase in the frequency of resistance; however, higher rates of movement produced an opposite trend. Carroll et al. (2012) developed a probabilistic model to compare RIB and a structured refuge when larval movement in a hypothetical population was considered, and concluded that RIB was more effective in delaying resistance evolution across a range of conditions. Both these studies illustrate the importance of studying larval movement and its implications for resistance evolution.

Differently from most of the work in this area, we used a spatially explicit model that allowed a detailed investigation of the effects of several variables on the spatial distribution of $S$. frugiperda. In addition, we used an individual-based model rather than a population-based model. The greatest advantage of this approach is the ability to represent the individual level-mechanisms and the variations among individuals during their life cycle (larval, pupal and adult stages; and different reproductive stages, i.e. pre-oviposition and oviposition), allowing a more realistic representation of the phenomenon under study (DeAngelis and Grimm, 2014). We also combined a larger set of conditions that were not previously modeled, to investigate the evolution of resistance, such as the type of resistance (complete and incomplete) with refuge configuration and refuge size, providing a more complete set of results.

\section{Model assumptions}

Spodoptera frugiperda is a holometabolous insect. Only larvae are exposed to the selection pressure imposed by the contact with $B t$ toxins, as only this stage feeds actively on Bt crops. Therefore, plants are damaged only by larvae, while adults are responsible for laying eggs on the leaves. In order to take this into account, a stochastic cellular automata consisting of a grid of $604 \times 604$ sites representing one plant available in each cell was proposed to simulate the population dynamics of larvae/pupae (immature stage) and adults, following a similar method to that of Garcia et al. (2014). Regarding the immature stage, a cell could be either empty or occupied by only one larva. This assumption was based on the mean number of larvae developed per maize plant, as reported by 
Farias et al. (2001). Although females lay clusters with hundreds of eggs on host plants, only one larva survives per plant, due to environmental pressure and larval cannibalism. Regarding adults, a cell could be empty or occupied by a maximum number of 10 adults, here set as the plant (cell) carrying capacity. Both stages were connected by adult emergence and oviposition. We assumed unlimited feeding resources. We also used a parallel update with fixed boundary conditions, i.e., the first and last rows and columns of cells were kept constant over time (both were equal to 0). Each time step $t$ corresponded to one day, and each cell of the CA represented $1 \times 1 \mathrm{~m}$ of the crop system. We also associated an agecounter with each insect represented in order to follow its chronological age. The immature stage was divided into larval and pupal stages, in order to represent the period of larval mobility. The rules are:

(1) Immature (larvae and pupae) population dynamics

(a) A cell occupied by an immature insect could become empty with probability $(1-\mu(i))+\sigma(i)$ due to mortality or adult emergence per day, respectively. Both parameters were dependent on the chronological age $i$ of the immature insect.

(b) An empty cell could become occupied by a larva if an adult (in a Moore neighborhood of radius 2 plus the central cell) laid eggs in it. Per-capita oviposition probability per day was $\phi(a)$, and was dependent on the chronological age $a$ of the adult.

\section{(2) Adult population dynamics}

(a) A cell would become empty of adults if all adults died. The mortality for an individual female per day is described by the probability $\gamma(a)$, depending on the chronological age $a$ of the adult.

(b) An empty cell could be occupied per day with probability $\sigma(i) / 2$ if a larva in the corresponding cell developed into a female adult. The fraction $1 / 2$ was related to the sex ratio, and the probability was dependent on the chronological age $i$ of the immature.

We considered an initial infestation in the center of the lattice, totaling 1600 individuals ( $40 \times 40$ cells). We chose $f=0.01$ as an initial frequency of the resistance allele. Therefore, 16 cells of the total of 1600 were randomly chosen to allocate resistant individuals. The parameter $\mu(\mathrm{i})$ (immature viability) was used to calculate the daily probability of immature mortality $(1-\mu(\mathrm{i}))$ as well as larval viabilities on $B t$ maize in the cases of either complete or incomplete resistance. A summary of the model parameters is presented in Table 1 .

All probability functions are described in Eqs. (1)-(4). They were proposed by using data on non-Bt maize plants from $S$. frugiperda populations provided by Barros et al. (2010).

Table 1

Model parameter units and description.

\begin{tabular}{ccc}
\hline Parameter & Unit & Description \\
\hline$\mu(i)$ & day $^{-1}$ & Probability per time that an immature insect survives \\
$\sigma(i)$ & day $^{-1}$ & Probability per time that a pupa becomes an adult \\
$\gamma(a)$ & day $^{-1}$ & Probability per time of death of a female adult \\
$\phi(a)$ & day $^{-1}$ & Probability per time of oviposition by a female adult \\
$f$ & - & Frequency of resistant allele \\
\hline
\end{tabular}

\section{Survival of immature insects}

$\left\{\begin{array}{l}\mu(i)=0.98 i f 0<i \leq 15(\text { corresponding to the larval stage }) \\ \mu(i)=0.96 i f 15<i \leq 25(\text { corresponding to the pupal stage) }\end{array}\right.$

\section{Metamorphosis (pupa becoming adult)}

$\left\{\begin{array}{l}\sigma(i)=0 \text { if } i<25 \\ \sigma(i)=1 \text { if } i=25(\text { at this age, all pupae developed into adults). }\end{array}\right.$

Mortality of adult insects

$$
\left\{\begin{array}{l}
\gamma(a)=0 \text { if } a \leq 11 \\
\gamma(a)=0.1(a-11)+0.5 \text { if } 11<a \leq 21 \\
\gamma(a)=1 \text { if } a>21
\end{array}\right.
$$

\section{Oviposition by a female adult}

$$
\left\{\begin{array}{l}
\phi(a)=0 \text { if } a \leq 3 \\
\phi(a)=0.7 \log \left(\left(\frac{1}{e^{0.3(a-1)}-0.3}\right)-\left(\frac{1}{e^{0.3 a}-0.3}\right)\right) \text { if } a>3 .
\end{array}\right.
$$

Since we used an individual-based model, each individual in the lattice was tested by these equations depending on whether it was an immature or an adult stage. For instance, in case of an immature, a random rational number between 0 and 1 was chosen by the computer, and if this number was less than 0.98 , the immature was considered to survive to the next time step. Otherwise, the individual would die.

According to Elmo et al. (2006), there is no preferential direction for adult dispersal. The distance traveled by an adult at each time step was calculated by using data for adult movement in maize fields (Vilarinho et al., 2011). Therefore, in Eq. (5), $P$ is the probability that an adult will travel over a distance $S$ per time step in the lattice if the number of insects in the cell destination is less than the carrying capacity defined previously (10 adults) (Fig. 1).

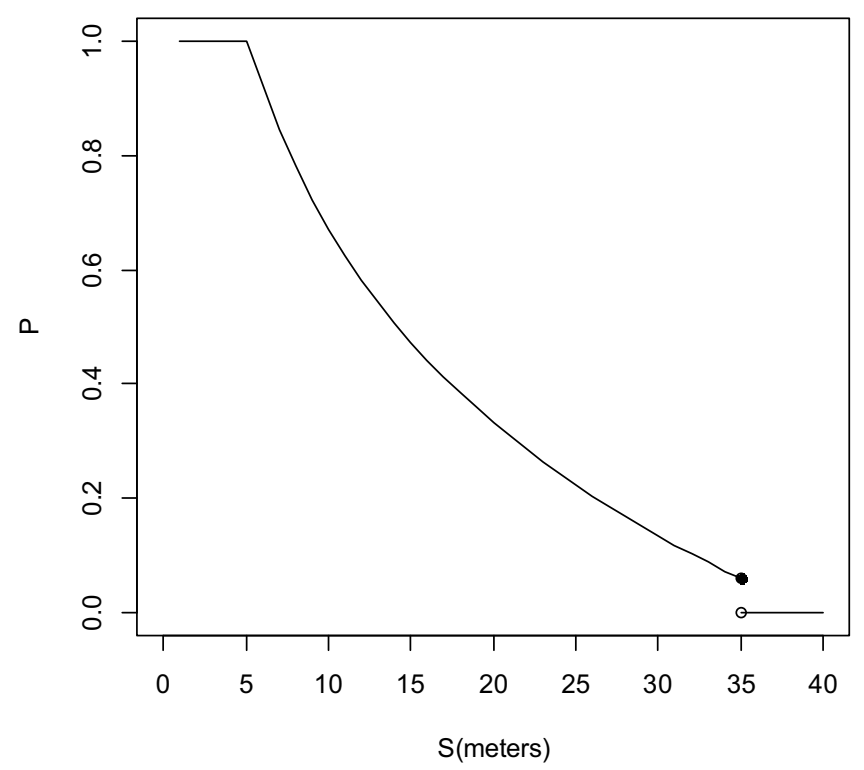

Fig. 1. Graphical representation of the equation system (5). $P$ represents the probability that an adult will travel over a distance $S$ per day. 


\section{Adult movement}

$P=1$ if $S \leq 5$ (all adults disperse over 5 meters per day)

$\left\{\begin{array}{l}P=-0.49 \ln (S)+1.8 \text { if } 5<S \leq 35 \\ P=0 \text { if } S>35 .\end{array}\right.$

Larval dispersal was implemented as a random movement (diffusion) into a Moore neighborhood of radius $1(3 \times 3$ neighborhood), because experimental evidence suggests that larvae disperse over only short distances. This means that on each day, a larva can move to any of the neighbor cells that are directly in contact with its cell. We considered that only a given proportion of all larvae could move in each time step (rate of dispersal). By increasing the proportion of larvae moving in each time step, larval dispersal in the lattice was increased. For instance, assuming a rate of dispersal equal to 0.1 means that only $10 \%$ of larvae (chosen randomly) are moving in the lattice per time step.

\subsection{Modeling the genetic component}

We considered a recessive and autosomal resistance to $B t$ maize ( $\mathrm{R}$ gene), determined by a single locus, and the existence of three different phenotypes (SS - susceptible homozygote, SR susceptible heterozygote, RR - resistant homozygote) (Vélez et al., 2014; Huang et al., 2014). In order to determine the genotype of each individual, we used the Hardy-Weinberg equation created by Hardy (1908) to study the genetic variation in a population for a single gene locus. It is expressed by:

$$
p^{2}+2 p q+q^{2}=1
$$

where $p$ is the frequency of the $S$ allele $(p=1-q)$ and $q$ is the frequency of the R allele. In Eq. (6) $p^{2}$ represents the frequency of the genotype SS, $2 p q$ determines the frequency of SR, and $q^{2}$ the frequency of RR.

The genetic contribution of females, but not males, to the offspring was known. The reason is that in the proposed model, the adult population is composed only of females since they are responsible for laying eggs, and as such cause the population to grow.

Thus, we needed to use Eq. (6) to estimate the conditional probabilities for each genotype, considering that we knew only the contribution of the parental female. For instance, if the mother is SS, we know the probability that the offspring genotype will be RR is equal to 0 . However, since the father's genotype is unknown, the offspring can be either SS or SR. For the offspring to be SS, the father would be SS $\left(p^{2}\right)$ or SR, and the probability that allele $\mathrm{S}$ will be transmitted to the offspring is given by $(0.5 * 2 * p q)$. For the offspring to be SR, the father would have to be SR and the R allele be transmitted to the offspring $\left(0.5 * 2^{*} p q\right)$, or the father would be $\mathrm{RR}\left(q^{2}\right)$. The complete conditional probabilities are shown in Table 2 .

\subsection{Fitness cost associated with resistance}

Gassmann et al. (2009) defined fitness cost as a condition in which fitness is increased by the presence of certain alleles under a

Table 2

Conditional probabilities of the occurrence of each offspring genotype, depending on the mother's genotype.

\begin{tabular}{cccc}
\hline Mother genotype & \multicolumn{3}{c}{ Offspring genotype } \\
\cline { 2 - 4 } & $\mathrm{SS}$ & $\mathrm{SR}$ & $\mathrm{RR}$ \\
\hline $\mathrm{SS}$ & $p^{2}+p q$ & $p q+q^{2}$ & 0 \\
$\mathrm{SR}$ & $0.5\left(p^{2}+p q\right)$ & $0.5\left(p^{2}+q^{2}\right)+p q$ & $0.5\left(q^{2}+p q\right)$ \\
$\mathrm{RR}$ & 0 & $p^{2}+p q$ & $q^{2}+p q$ \\
\hline
\end{tabular}

stress condition (e.g., resistance to Bt crops), but fitness is reduced when individuals carrying these alleles are freed from this stress condition (e.g., resistance to $B t$ crops in the absence of $B t$ crops). The existence of fitness costs associated with resistance to $B t$ toxins has been intensively discussed for $S$. frugiperda. No fitness cost was associated with resistance in populations of $S$. frugiperda from Puerto Rico (Jakka, 2013), but a high fitness cost was detected in populations from Florida (Dangal and Huang, 2015). In this study, we assumed a reduction of $20 \%$ in daily larval viability and a delay of four days in the duration of larval development in the absence of $B t$ crops when individuals carried at least one copy of the resistance allele (RR or SR genotypes) (Dangal and Huang, 2015). According to Barros et al. (2010), the daily larval viability on leaves of non-Bt maize is 0.98 ; therefore, larval viability was reduced to 0.78 daily. The delay in larval development was considered by changing the domain of functions (1) and (2) (Eqs. (7) and (8)).

$\left\{\begin{array}{l}\mu(i)=0.78 \text { if } 0<i \leq 15+4(\text { corresponding to the larval stage }) \\ \mu(i)=0.96 \text { if } 15+4<i \leq 25+4(\text { corresponding to the pupal stage) }\end{array}\right.$

$\left\{\begin{array}{l}\sigma(i)=0 \text { if } i<25+4 \\ \sigma(i)=1 \text { if } i=25+4(\text { at this age,all pupae developed into adults })\end{array}\right.$

\subsection{Simulations}

To measure the effect of larval dispersal and refuge configuration on the proportion of resistant larvae, we constructed several spatial arrangements composed of $B t$ maize and non- $B t$ maize in refuge areas with different sizes and configurations. Three refuge configurations were tested in the simulations: seed mixture, blocks, and strips (Fig. 2). The proportions of the refuges with nonBt maize ranged from 20 to $50 \%$. Bt maize was considered to produce a high-dose event, which, according to the US Environmental Protection Agency guidelines, should kill 99.99\% of the susceptible individuals in the field, with a minimum mortality of 95\% of the heterozygotes (Environmental Protection Agency, 1998). When resistance was complete, we considered that the survival of $B t$-resistant larvae (RR) in $B t$ maize areas was the same as that of homozygote larvae (SS) in non-Bt maize. On the other hand, when resistance was incomplete, larval survival of the RR genotype in $B t$ maize was reduced by $50 \%$; therefore, the survivorship of the RR genotype in non- $B t$ maize was higher even in the presence of a fitness cost associated with resistance. Thus, in the case of incomplete resistance, resistant and susceptible larvae competed for non-Bt cells. Fig. 3 explains the different values assumed by the parameter $\mu(\mathrm{i})$ during the larval stage in the different simulated conditions. A summary of the initial conditions used in our simulations is shown in Table 3 .

The use of seed mixtures as a refuge strategy has been a concern, as some investigators have argued that larvae carrying a resistance allele may use refuge areas to reach advanced instars, and become large enough to survive $B t$ toxins (sub-lethal dose) (Onstad et al., 2011; Yang et al., 2014; Sorgatto et al., 2015). In order to test this possibility, we considered that $B t$ toxins would affect only larvae less than six days old (earlier than 4 th instar). For each proportion of non-Bt area and each refuge configuration, we tested three different rates of larval dispersal (0, 0.1 and 0.5$)$. Each simulation was conducted during 300 time steps and repeated 50 times. Therefore, the results presented in the next section are the mean values of the proportion of resistant larvae in these 50 
a)

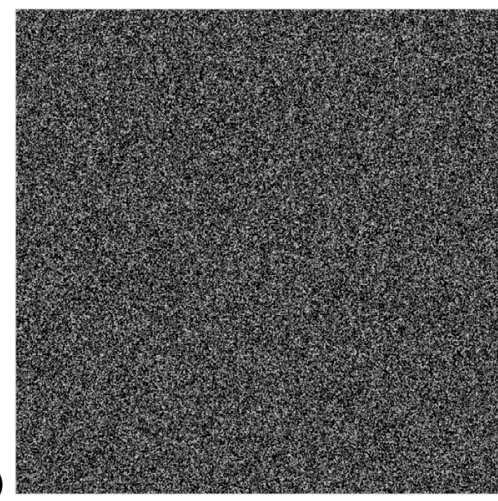

b)

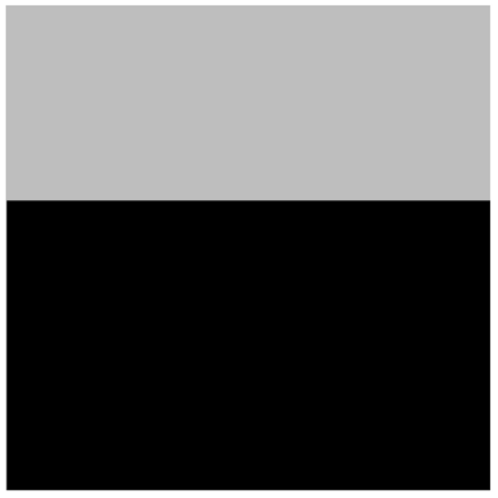

c)

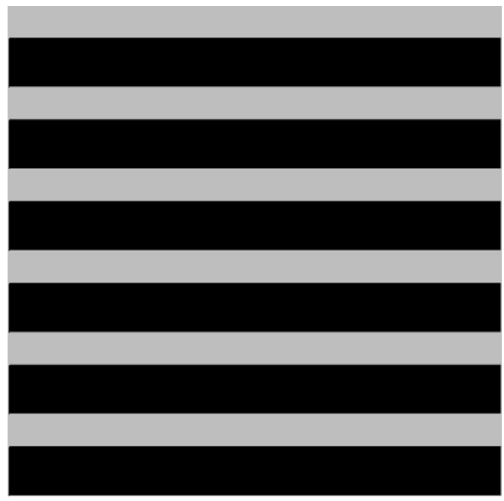

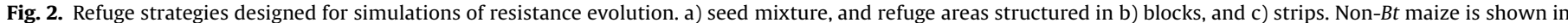
gray, and Bt maize in black. Spatial arrangements with $40 \%$ refuge areas are illustrated.

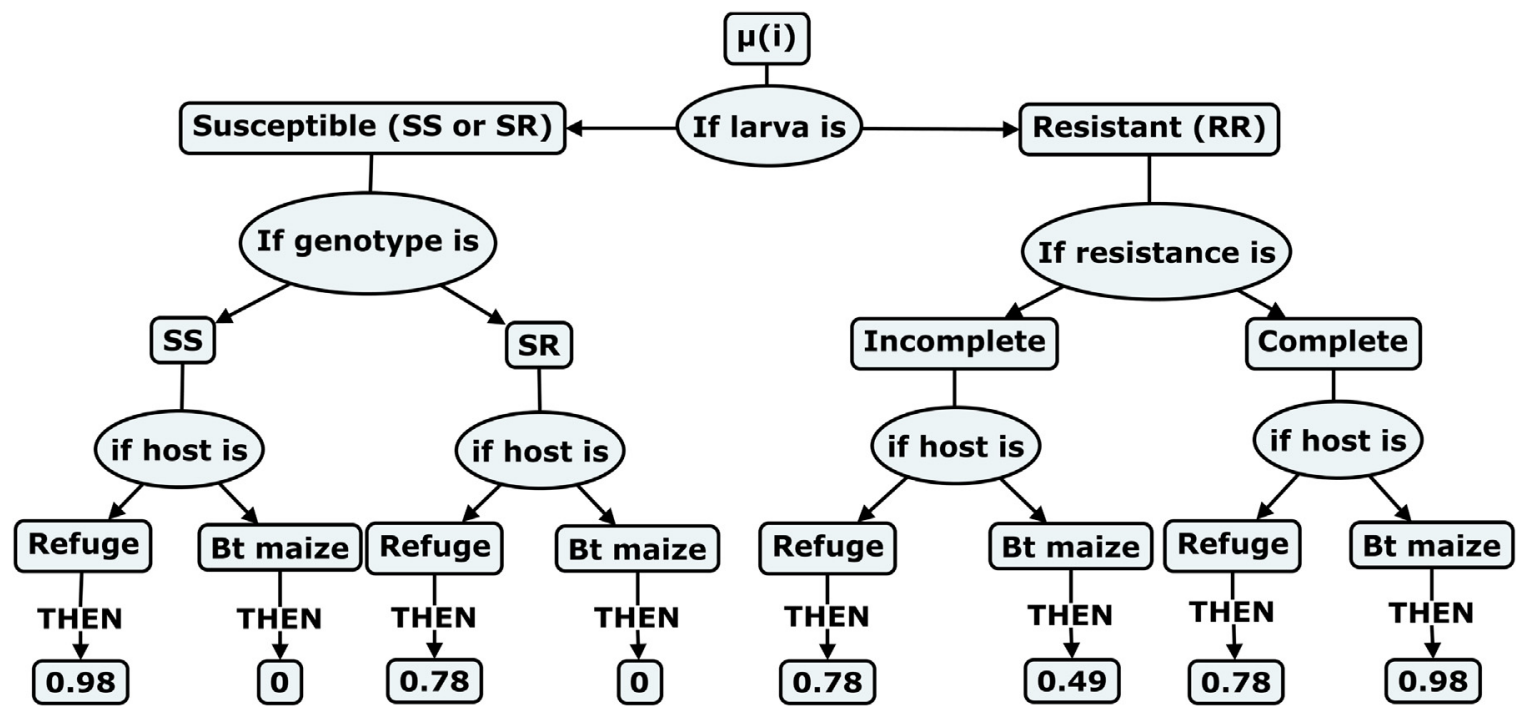

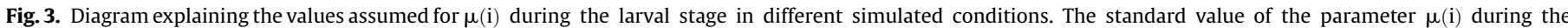
larval stage is equal to 0.98 as described in Eq. (1).

repetitions. All means were compared by using the Tukey's test at $5 \%$ probability to determine if they were significantly different.

\section{Results}

In the proposed model, the efficiency of resistant larvae in exploiting different areas depended on three main factors: resistance type, rate of larval movement, and refuge size. The proportion of resistant insects affected by these factors in each simulation is shown in Fig. 4.

\subsection{Seed mixture configuration}

The spatial distribution of $S$. frugiperda larvae in the seedmixture configuration is shown in Fig. 5a. No significant difference

Table 3

Overview of the initial conditions used in the simulations. All possible combinations among the described variables were simulated.

\begin{tabular}{rccc}
\hline Resistance type & Larval movement & Refuge configuration & Refuge size (\%) \\
\hline Incomplete & 0 & Seed mixture & 20 \\
Complete & 0.1 & Blocks & 30 \\
& 0.5 & Strips & 40 \\
& & & 50
\end{tabular}

in the proportion of resistant insects was found for the $50 \%$ seed mixture, because $B t$ and non- $B t$ areas were distributed homogeneously and in the same proportion, reducing the effect of larval movement on the proportion of resistant larvae. When the seed mixture with non-Bt maize was reduced to $40 \%$, with either complete or incomplete resistance, the higher the proportion of larvae dispersing to neighbor cells, the higher was the proportion of resistant insects in the population (Fig. 4c and d). This pattern also occurred with a 30\% refuge area, when resistance was complete (Fig. 4f). With a 30\% refuge area and when resistance was incomplete, larval movement still increased the proportion of resistant larvae (Fig. 4e). However, an intermediate dispersal rate (0.1) increased this proportion more than a high dispersal rate (0.5). When the refuge size was reduced to $20 \%$ (Fig. $4 \mathrm{~g}$ and $\mathrm{h}$ ), the dominance of resistant insects was higher and the patterns of resistance evolution observed in the refuge size of $30 \%$ began to disappear since the spatial configuration became more homogeneous.

\subsection{Block configuration}

The simulations of the evolution of resistance to Bt crops when using refuge areas structured in a block configuration, arranged in two separate areas, showed a spatial polarization between an area 


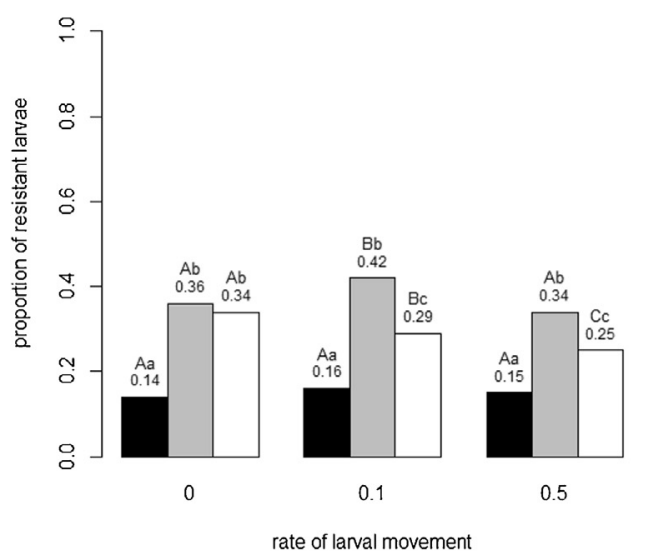

a) Incomplete resistance $(50 \%)$

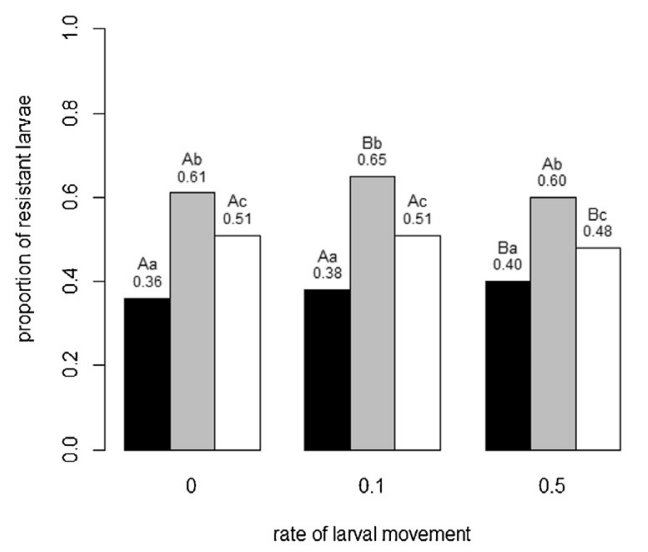

c) Incomplete resistance (40\%)

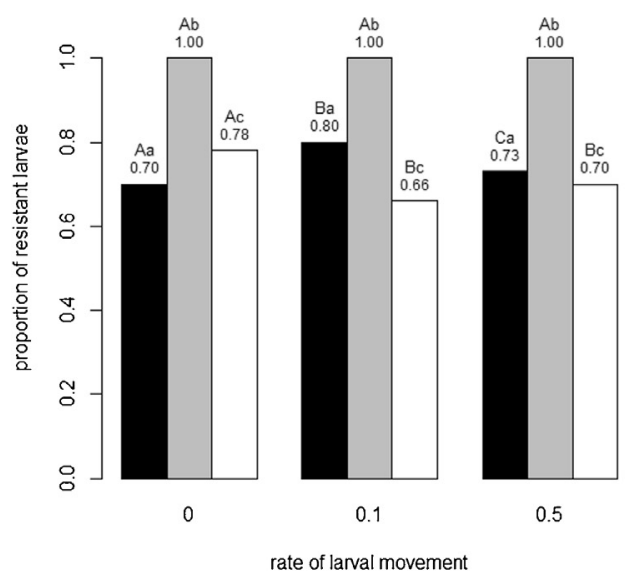

e) Incomplete resistance (30\%)

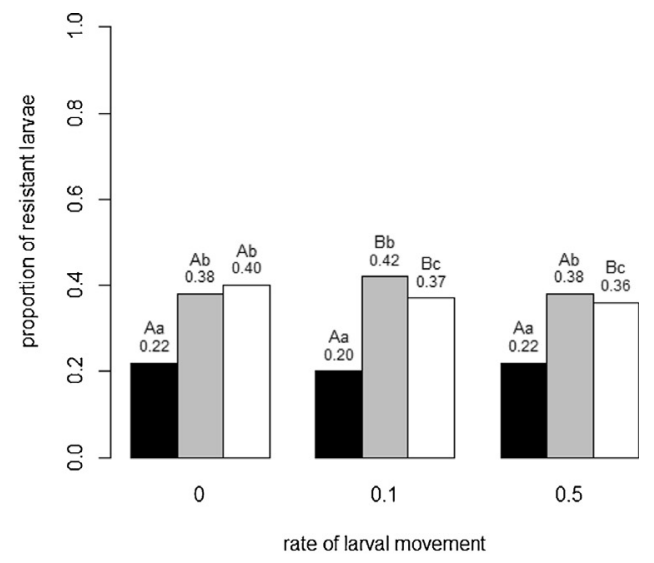

b) Complete resistance (50\%)

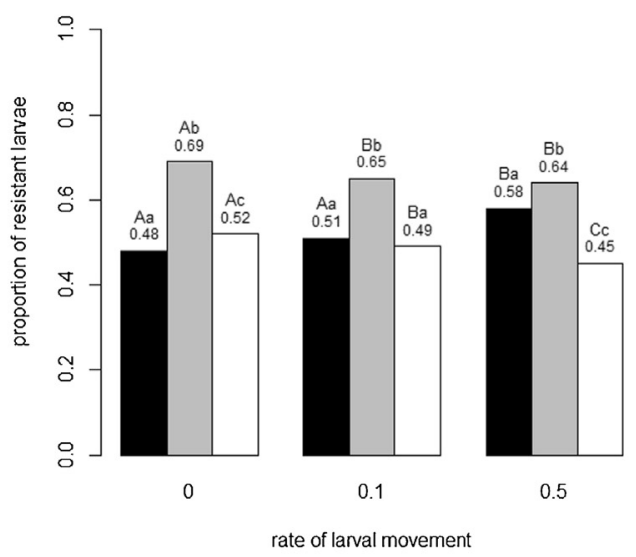

d) Complete resistance (40\%)

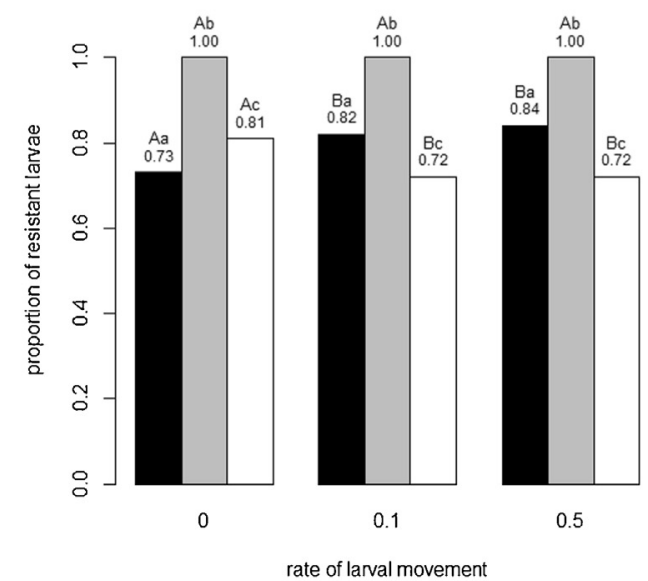

f) Complete resistance (30\%)

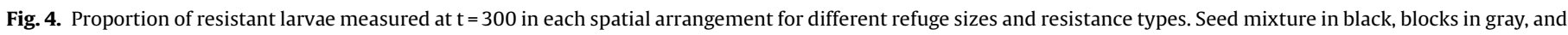

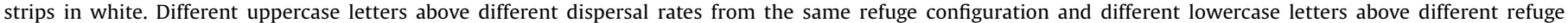
configurations from the same dispersal rate indicate significant differences at the $5 \%$ level (Tukey's HSD, p $<0.05$ ). 


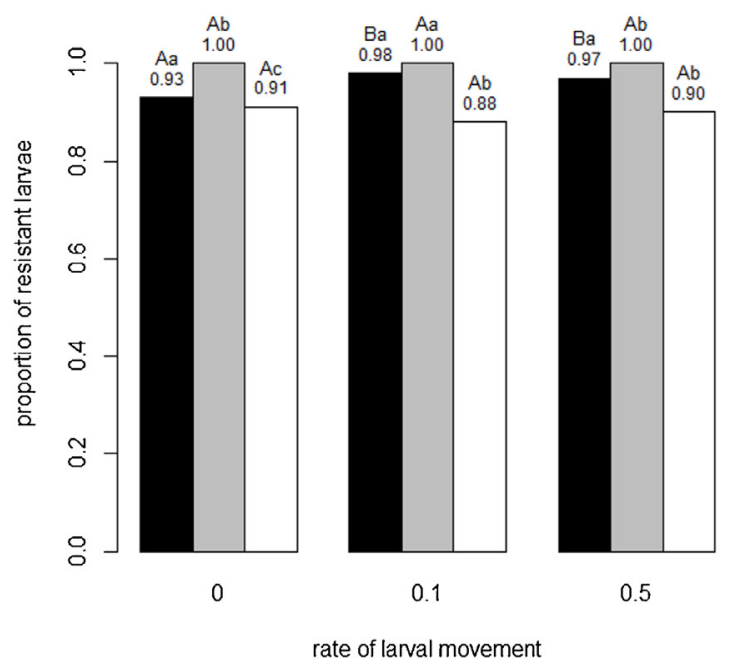

g) Incomplete resistance (20\%)

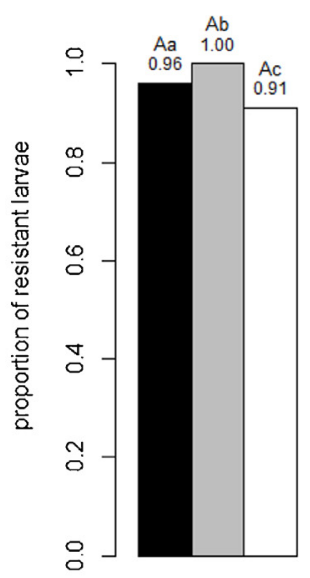

0

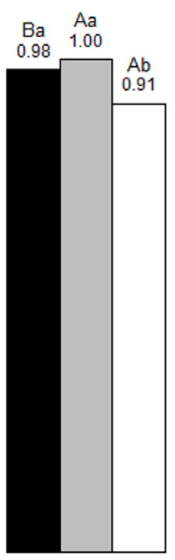

0.1

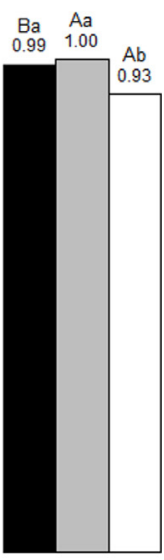

0.5 rate of larval movement

\section{h) Complete resistance (20\%)}

Fig. 4. (Continued)

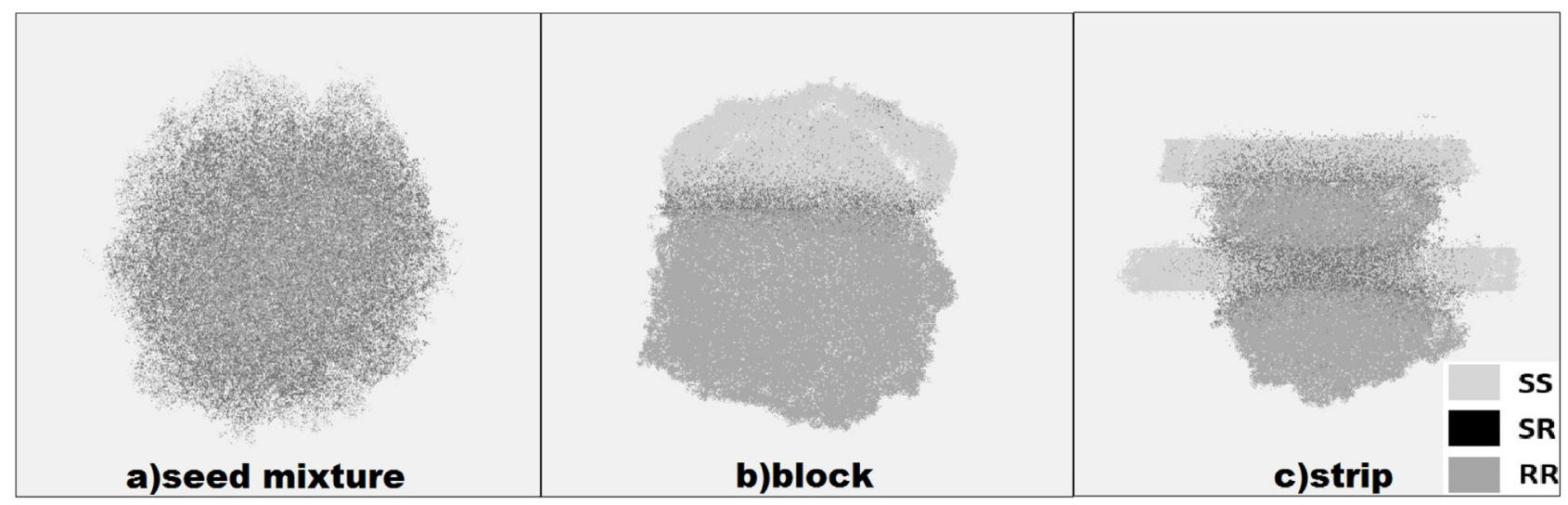

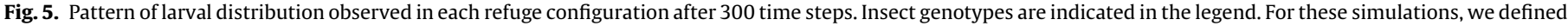
spatial arrangements with $40 \%$ refuge areas, complete resistance and rate of larval movement equal to 0.5 .

occupied preferentially by SS larvae (non-Bt block) and another area occupied by RR larvae (Bt block) (Fig. 5b). Heterozygous (RS) larvae predominated at the boundaries of the $B t$ and non- $B t$ areas, since crossings between SS and RR genotypes occurred in a high proportion in this area. In this refuge arrangement, larval movement affected the evolution of resistance only in areas with 40 and $50 \%$ refuge area, regardless of the type of resistance (Fig. $4 \mathrm{a}-\mathrm{d}$ ), whether incomplete or complete. When the refuge area was reduced to 30 and $20 \%$ of the total, non- $B t$ blocks were strongly reduced, resulting in a more homogeneous area, and resistant larvae completely dominated the population.

When resistance was incomplete, the highest proportion of resistant larvae occurred when the movement rate was equal to 0.1 , with refuge sizes of 40 and $50 \%$ (Fig. $4 a, c$ ). The same pattern was found in a refuge size of $50 \%$, when resistance was complete (Fig. 4b). The highest proportion of resistant individuals carrying complete resistance to $B t$ maize in a refuge size of $40 \%$ was observed in the absence of larval movement (Fig. 4d).

\subsection{Strip configuration}

In this refuge configuration (Fig. 5c), the highest proportion of resistant larvae occurred in the absence of larval movement in most of the refuge sizes tested, regardless of the type of resistance (incomplete or complete) (Fig. 4). Larval movement benefited susceptible genotypes, accelerating the occupation of non-Bt strips (horizontal movement). In a refuge size of $20 \%$, the spatial configuration was sufficiently homogeneous to reduce the effect of larval movement, and the results were not significantly different.

\section{Discussion}

The increase in the proportion of resistant larvae as larval movement increased in the seed mixture with complete (30 and $40 \%$ ) and incomplete (40\%) resistance occurred because susceptible larvae moved to their neighbor cells, which were mostly composed of $B t$ maize, resulting in their death, reducing their 


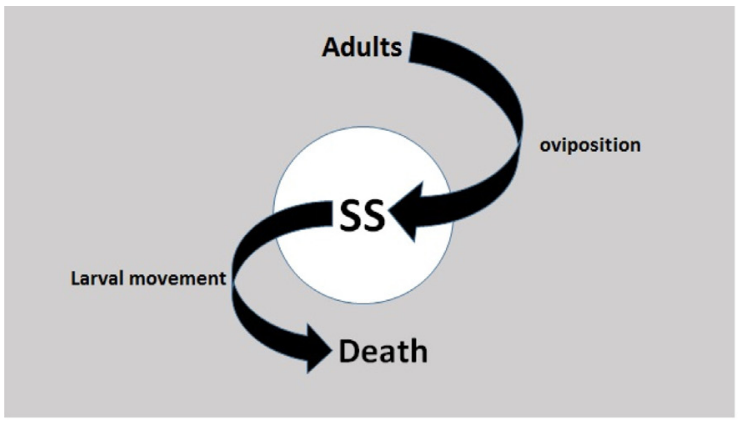

a) SS larvae

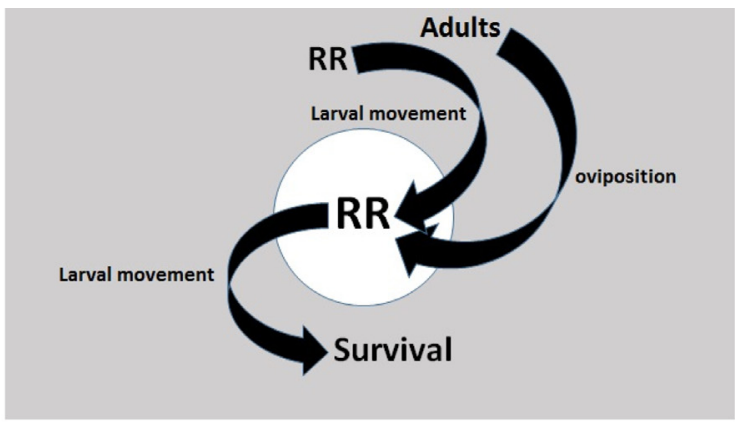

b) RR larvae

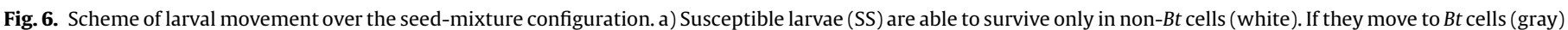
before reaching the 4 th instar, they die. b) Resistant larvae survive in either non-Bt cells or $B t$ cells.

number and increasing the proportion of resistant larvae (Fig. 6). As the SS larvae moved and died, non-Bt cells became unoccupied and free for colonization by RS (heterozygous) or RR (homozygous) larvae, which increased in the population. Such a pattern has been intensively discussed previously, and accelerated resistance due to larval movement in spatial arrangements composed of $B t$ and nonBt crops has also been modeled (Carroll et al., 2012). In a field study, Head et al. (2014) also observed that a low number of Diabrotica speciosa (Coleoptera: Chrysomelidae) larvae were able to move from $B t$ to non- $B t$ areas when a seed mixture was used as a refuge strategy. According to a field study conducted by Wangila et al. (2013), either heterozygotes or resistant larvae (in the case of incomplete resistance) might remain in non-Bt maize until they grow large enough to enhance their survival chances in $B t$ maize, increasing their number in the population.

In the case of incomplete resistance (30\%), a dispersal rate of 0.1 resulted in the highest proportion of resistant insects, because in this case, survival of resistant larvae in non-Bt maize was higher than in $B t$ maize. When the dispersal rate was too high, larvae moved too rapidly and increased their probability of reaching a cell with $B t$ maize, resulting in the death of RS genotypes or reduced survival of RR genotypes.

The polarization pattern observed in the block configuration occurs because the border between $B t$ and non-Bt crops is limited to only one contact zone between them, which allows susceptible individuals to become isolated from resistant ones in non-Bt areas (Fig. 7a). An intermediate movement rate (0.1) accelerated the evolution of resistance in this configuration because at this rate, dispersal was sufficiently rapid to maintain the flow of different genotypes between cells near the border between $B t$ and non-Bt blocks (SS larvae moved and died in the $B t$ block), but low enough to prevent them from moving out of the border. At a higher rate of movement (0.5), susceptible and resistant larvae moved in opposite directions far from the border, reducing the mortality of susceptible larvae and allowing the densities of resistant (RR) and susceptible (SS and SR) larvae to increase without affecting each other (spatial isolation). In a refuge size of $50 \%$, when resistance was complete, resistant larvae were favored by remaining in $B t$ cells instead of competing with susceptible larvae for non-Bt cells, because of the associated fitness cost; therefore, the evidence of the relationship between larval movement and the proportion of resistant individuals shown was weaker. The exception occurred when resistance was complete and refuge areas occupied $40 \%$ of the total area, because Bt maize occupied most of the area, enhancing the survival of resistant larvae. The survival of susceptible larvae increased at higher movement rates as they moved far from the $B t$ block, and at the same time the survival of resistant larvae decreased because they moved to non$B t$ cells (reduced survival in case of complete resistance, due to fitness cost). Onstad et al. (2011) obtained similar results when comparing refuge strategies, e.g. a refuge structured in blocks against a seed mixture. They reported that seed mixtures eliminate the spatial isolation between the susceptible and resistant phenotypes, differently from block configurations. In addition, crosses between susceptible and resistant insects were only observed along the boundaries of $B t$ and non-Bt blocks. Mating

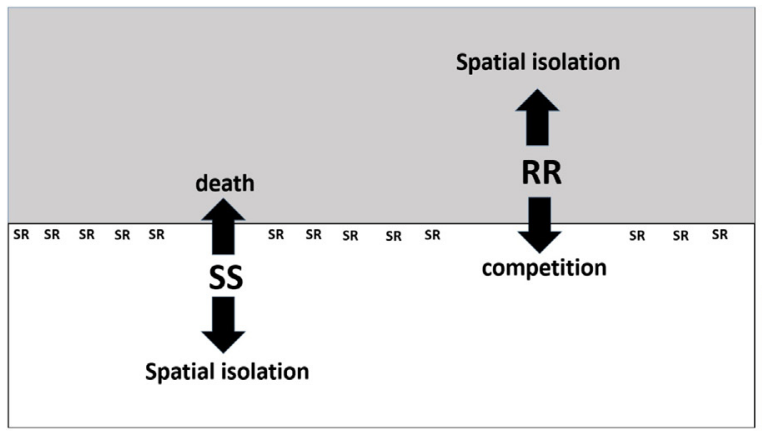

a) Blocks

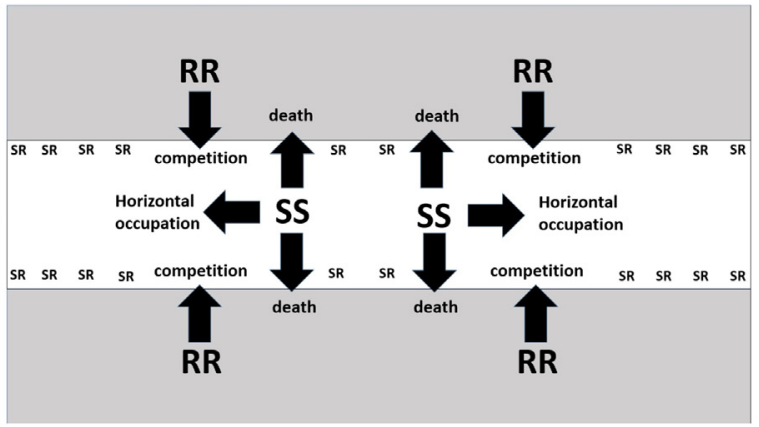

b) Strips

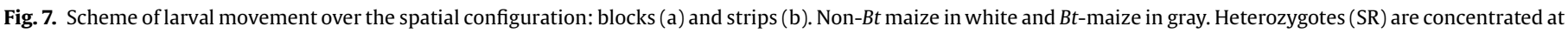
the boundaries between $B t$ and non-Bt maize. 
between $B t$-resistant adults took place more frequently in refuge areas structured as blocks than in areas with seed mixtures, reflecting the expectations of Carroll et al. (2012).

In a strip configuration, the more rapid occupation of non-Bt strips by susceptible larvae prevented resistant genotypes from occupying these areas (Fig. 7b). The competitive advantage of susceptible larvae over resistant larvae in non-Bt strips severely affected the resistant insects in the case of incomplete resistance, because the competition for non-Bt cells was more intense, since the resistant larvae reached their highest survival rate in these cells. With a refuge size of $20 \%$, the spatial configuration was sufficiently homogeneous to reduce the effect of larval movement. Comparing the refuge structured in strips to the other refuge strategies tested, we observed that the strip configuration maintained the heterogeneity in the area (preventing mating between $B t$-resistant adults), and continuous areas of non-Bt maize arranged as strips allowed susceptible insects to persist.

Comparing the three configurations, we can conclude that the border between $B t$ and non-Bt crops plays an important role in resistance evolution. The block configuration has the smallest border zone between $B t$ and non-Bt blocks, and was the least effective arrangement for delaying evolution. For either complete or incomplete resistance, the population becomes completely dominated by resistant individuals when the refuge area is less than $40 \%$. The resulting reduction of borders between $B t$ and non$B t$ blocks favors the isolation of genotypes, reducing the intercrossing that would "dilute" the resistance allele. On the other hand, the seed mixture provides the largest border of contact between $B t$ and non-Bt areas, since they are randomly distributed. This is the best arrangement to delay resistance evolution, in either incomplete or complete resistance, when the refuge area is higher than $30 \%$. However, as the proportion of refuge is reduced, the strip configuration becomes the most suitable. This occurs, in part, because of the effect of larval movement. However, this is also observed when the refuge area is $20 \%$ and the larvae are not moving. We can conclude that for the seed mixture, at this proportion ( $20 \%$ refuge), the non- $B t$ cells are so dispersed and scarce in the lattice that the effect is similar to a homogeneous $B t$ crop.

Our findings indicate that the best option for farmers is to arrange refuge areas in order to maximize the borders of contact between $B t$ and non- $B t$ plants, but it is also necessary to consider the effect of larval movement on the system. The ideal arrangement would maintain continuous refuge areas to allow the maintenance of SS individuals, but it would also have the largest possible border zone between refuge and $B t$ crops. In our case, the strip configuration satisfied both of these requirements better than the other two arrangements. The block configuration offered a continuous refuge, but the contact between the different crops was reduced to one boundary line. On the other hand, the seed configuration offered the largest contact surface between $B t$ and non-Bt crops, but it restricted the SS larvae to isolated "islands" of refuge where exiting these islands would lead them to death and free those cells for occupation by RR larvae.

Although the spatial structure in agricultural systems is more complex, involving different crops and even interspecific interactions among insects, including other pests and beneficial species, our model gives an overall view of the role of the variables studied, such as the spatial configuration, resistance type, and larval movement, on the evolution of resistance in insects. In the field, the complexity of each structure would make such a study impossible, considering all the particularities of each case. Therefore, the computational approach is advantageous, as it allows for the investigation of the general characteristics of a particular system. Moreover, modeling is a continuous process and the successful validation of a theoretical model requires a thorough understanding of all variables involved. According to Rykiel (1996), validation is not a test of a scientific theory, nor is it a statement of the veracity of a scientific understanding. Validation signifies that a model is acceptable for its purpose since it meets the predetermined requirements. In this stage, a specific landscape can be structured in our simulation, considering all of its particularities, to allow for local comparisons.

\section{Conclusions}

In general, larval movement led to an increase in the proportion of resistant insects in the population for the seed-mixture configuration, because it favored the occupation of non-Bt cells by resistant larvae. The opposite trend was observed for the strip configurations, because larval movement favored the occupation of non-Bt strips by susceptible larvae, which limited the movement of resistant ones. In the case of the block configurations, the highest proportion of resistant larvae was observed at a rate equal to 0.1 , because it was high enough to maintain the flow of RR and SS genotypes between $B t$ and non-Bt blocks, but low enough to prevent their movement out of these blocks, leading to spatial isolation.

We also combined these results with the effect of the border zone between $B t$ and non-Bt areas on the evolution of resistance. In order to successfully fulfill the objectives of a refuge implementation, it is necessary to establish continuous refuge areas (maintenance of SS individuals) as well as large border zones to promote crossing between resistant and susceptible insects. The arrangement that best fulfilled these conditions was the strip configuration. Indeed, as observed in our results, the strip configuration was most effective in delaying the evolution of resistance.

\section{Acknowledgements}

AG holds fellowships awarded by FAPESP (2015/10640-2, 2016/ 00831-8). The project also receives grants 2014/16277-4 and 2014/ 16609-7 from FAPESP. Work by WACG and FLC has been supported by research fellowships from the Conselho Nacional de Desenvolvimento Científico e Tecnológico. We are also grateful for the assistance of Dr. Jorge Torres with complementary data on $S$. frugiperda. We are thankful for the assistance of Dr. Janet Reid with English revision.

\section{Appendix A. Supplementary data}

Supplementary data associated with this article can be found, in the online version, at http://dx.doi.org/10.1016/j. ecocom.2016.07.006.

\section{References}

Barros, E.M., Torres, J.B., Bueno, A.F., 2010. Oviposition, development, and reproduction of Spodoptera frugiperda (J.E. Smith) (Lepidoptera: Noctuidae) fed on different hosts of economic importance. Neotrop. Entomol. 39, 996-1001.

Binning, R.R., Coats, J., Kong, X., Hellmich, R.L., 2014. Susceptibility and aversion of Spodoptera frugiperda (Lepidoptera: Noctuidae) to Cry1F Bt Maize and considerations for insect resistance management. J. Econ. Entomol. 107, 268374.

Carroll, M.W., Head, G., Caprio, M., 2012. When and where a seed mix refuge makes sense for managing insect resistance to Bt plants. Crop Prot. 38, 74-79.

Carroll, M.W., Head, G., Caprio, M., Stork, L., 2013. Theoretical and empirical assessment of a seed mix refuge in corn for southwestern corn borer. Crop Prot. 49, 58-65.

Cerda, H., Wright, D.J., 2004. Modeling the spatial and temporal location of refugia to manage resistance in Bt transgenic crops. Ecosyst. Environ. 102, 163-174.

Crowder, D.W., Carrière, Y., 2009. Comparing the refuge strategy for managing the evolution of insect resistance under different reproductive strategies. J. Theor. Biol. 261, 423-430. 
Dangal, V., Huang, F., 2015. Fitness costs of Cry1F resistance in two populations of fall armyworm Spodoptera frugiperda (J.E. Smith), collected from Puerto Rico and Florida. J. Invertebr. Pathol. 127, 81-86.

DeAngelis, D.L., Grimm, V., 2014. Individual-based models in ecology after four decades. F1000Prime Reports. v.6. 10.12703/P6-39

Elmo, E.P., Fernandes, M.G., Degrande, P.E., Cessa, R.M.A., Salomão, J.L., Nogueira, R. F., 2006. Spatial distribution of plants infested with Spodoptera frugiperda (J.E. Smith) (Lepidoptera: Noctuidae) on corn crop. Neotrop. Entomol. 35, 689-697.

Environmental Protection Agency, 1998. Final Report of the Subpanel on Bacillus thuringiensis (Bt) Plant-Pesticides and Resistance Management. Available from http://www2.epa.gov/sap (accessed September 2015).

Farias, P.R.S., Barbosa, J.C., Busoli, A.C., 2001. Spatial distribution of fall armyworm, Spodoptera frugiperda (J.E. Smith) (Lepidoptera: Noctuidae), on corn crop. Neotrop. Entomol. 30, 681-689.

Farias, J.R., Andow, D.A., Horikoshi, R.J., Sorgatto, R.J., Fresia, P., Santos, A.C., de Omoto, C., 2014. Field-evolved resistance to Cry1 F maize by Spodoptera frugiperda (Lepidoptera: Noctuidae) in Brazil. Crop Prot. 64, 150-158.

Garcia, A., Cônsoli, F.L., Godoy, W.A.C., Ferreira, C.P., 2014. A mathematical approach to simulate spatio-temporal patterns of an insect-pest, the corn rootworm Diabrotica speciosa (Coleoptera: Chrysomelidae) in intercropping systems. Landsc. Ecol. 29, 1531-1540.

Gassmann, A.J., Carrière, Y., Tabashnik, B.E., 2009. Fitness costs of insect resistance to Bacillus thuringiensis. Annu. Rev. Entomol. 54, 147-163.

Hardy, G.H., 1908. Mendelian proportions in a mixed population. Science 28, 49-50.

Head, G. Campbell, L A Carroll, M. Clark T Galvan, T. Hendrix, W.M., Prasifka, P.L. Price, P., Storer, N.P., Stork, L., 2014. Movement and survival of corn rootworm in seed mixtures of SmartStax ${ }^{\mathbb{B}}$ insect-protected corn. Crop Prot. 58, 14-24.

Hiebeler, D., 2005. Spatially correlated disturbances in a locally dispersing population model. J. Theor. Biol. 232, 143-149.

Huang, F., Qureshi, J.A., Meagher R.L.Jr. Reisig, D.D., Head, G.P., Andow, D.A., Ni, X., Kerns, D., Buntin, G.D., Niu, Y., Yang, F., Dangal, V., 2014. Cry1F resistance in fall armyworm Spodoptera frugiperda: single gene versus pyramided Bt maize. PLoS One 9 (11), e112958.

Jakka, S.R.K., 2013. Characterization of Field Evolved Resistance to Transgenic Cry1Fa Maize in Spodoptera Frugiperda Dissertation. University of Tennessee.

James, C., 2013. Global Status of Commercialized Biotech/GM Crops: 2013. ISAAA New York.

Jorgensen, S.E., Chon, T.S., 2009. Model types available for ecological modelling. In: Jorgensen, S.E., Chon, T.S., Friedrich, R. (Eds.), Handbook of Ecological Modelling and Informatics.. WIT Press, Southampton UK, pp. 9-40.

Kang, J., Huang, F., Onstad, D.W., 2014. Modeling evolution of resistance of sugarcane borer (Lepidoptera: Crambidae) to transgenic Bt corn. Environ. Entomol. 45, 1084-1104.

Kranthi, K.R., Kranthi, N.R., 2004. Modelling adaptability of cotton bollworm, Helicoverpa armigera (Hübner) to Bt cotton in India. Curr. Sci. 87, 1096-1107.

Ministry of Agriculture, Livestock and Food Supply. 2014. Recomendações de refúgio preconizadas pelas empresas detentoras das tecnologias. Memória da 1á reunião do GTMR (Grupo Técnico-Científico sobre Manejo de Resistência).
Omoto, C., Bernardi, O., Salmeron, E., Sorgatto, R.J., Dourado, P.M., Crivellari, A., Carvalho, R.A., Willse, A., Martinelli, S., Head, G.P., 2016. Field-evolved resistance to Cry1Ab maize by Spodoptera frugiperda in Brazil. Pest Manage. Sci. doi:http:// dx.doi.org/10.1002/ps.4201.

Onstad, D.W., Mitchell, P.D., Hurley, T.M., Lundgren, J.G., Porter, R.P., Krupke, C.H., Spencer, J.L., DiFonzo, C.D., Baute, T.S., Hellmich, R.L., Buschman, L.L., Hutchison, W.D., Tooker, J.F., 2011. Seeds of change: corn seed mixtures for resistance management and integrated pest management. J. Econ. Entomol. 104, 342-352.

Rykiel Jr., E.J., 1996. Testing ecological models: the meaning of validation. Ecol. Modeling 90, 229-244.

Sisterson, M.S., Carrière, Y., Dennehy, T.J., Tabashnik, B.E., 2005. Evolution of resistance to transgenic crops: interaction between insect movement and field distribution. J. Econ. Entomol. 98, 1751-1762.

Sorgatto, R.J., Bernardi, O., Omoto, C., 2015. Survival and development of Spodoptera frugiperda and Chrysodeixis includens (Lepidoptera: noctuidae) on Bt cotton and implications for resistance management strategies in Brazil. Environ. Entomol. 44, 186-192.

Sparks, A.N., 1979. A review of the biology of the fall armyworm. Fla. Entomol. 62, $82-87$.

Téllez-Rodríguez, P., Raymond, B., Morán-Bertot, I., Rodríguez-Cabrera, L., Wright, D. J., Borroto, C.G., Ayra-Pardo, C., 2014. Strong oviposition preference for Bt over non-Bt maize in Spodoptera frugiperda and its implications for the evolution of resistance. BMC Biol. 12, 48. doi:http://dx.doi.org/10.1186/1741-7007-12-48.

Tabashnik, B.E., Brévault, T., Carrière, Y., 2013. Insect resistance to Bt crops: lessons from the first billion acres. Nat. Biotechnol. 31, 510-521.

Thacker, J.R.M., 2002. An Introduction to Arthropod Pest Control. Cambridge University Press, Cambridge.

Tyutyunov, Y., Zhadanovskaya, E., Bourguet, D., Arditi, R., 2008. Landscape refuges delay resistance of the European corn borer to Bt-maize: a demo-genetic dynamic model. Theor. Popul. Biol. 74, 138-146.

Vélez, A.M., Spencer, T.A., Alves, A.P., Moellenbeck, D., Meagher, R.L., Chirakkal, H., Siegfried, B.D., 2013. Inheritance of Cry1F resistance, cross-resistance and frequency of resistant alleles in Spodoptera frugiperda (Lepidoptera: Noctuidae). Bull. Entomol. Res. 103, 700-713.

Vélez, A.M., Spencer, T.A., Alves, A.P., Crespo, A.L.B., Siegfried, B.D., 2014. Fitness costs of Cry1F resistance in fall armyworm, Spodoptera frugiperda. J. Appl. Entomol. 128, 315-325.

Vilarinho, E.C., Fernandes, O.A., Hunt, T.E., Caixeta, D.F., 2011. Movement of Spodoptera frugiperda adults (Lepidoptera: Noctuidae) in maize in Brazil. Fla. Entomol. 94, 480-488.

Wangila, D.S., Leonard, B.R., Ghimire, M.N., Bai, Y., Zhang, L., Yang, Y., Emfinger, K.D., Head, G.P., Yang, F., Niu, Y., Huang, F., 2013. Occurrence and larval movement of Diatraea saccharalis (Lepidoptera: Crambidae) in seed mixes of non-Bt and Bt pyramid corn. Pest Manage. Sci. 69, 1163-1172.

Yang, F., Kerns, D.L., Head, G.P., Leonard, B.R., Levy, R., Niu, Y., Huang, F., 2014. A challenge for the seed mixture refuge strategy in Bt maize: impact of crosspollination on an ear-feeding pest, corn earworm. PLoS One 9 (11), e112962. 